\title{
The neurocircuitry of illicit psychostimulant addiction: acute and chronic effects in humans
}

\author{
This article was published in the following Dove Press journal: \\ Substance Abuse and Rehabilitation \\ 7 February 2013 \\ Number of times this article has been viewed
}

\author{
Sara B Taylor ${ }^{\prime}$ \\ Candace R Lewis' \\ $M$ Foster Olive ${ }^{1,2}$ \\ 'Program in Behavioral Neuroscience, \\ ${ }^{2}$ Interdisciplinary Graduate Program \\ in Neuroscience, Arizona State \\ University, Tempe, AZ, USA
}

\begin{abstract}
Illicit psychostimulant addiction remains a significant problem worldwide, despite decades of research into the neural underpinnings and various treatment approaches. The purpose of this review is to provide a succinct overview of the neurocircuitry involved in drug addiction, as well as the acute and chronic effects of cocaine and amphetamines within this circuitry in humans. Investigational pharmacological treatments for illicit psychostimulant addiction are also reviewed. Our current knowledge base clearly demonstrates that illicit psychostimulants produce lasting adaptive neural and behavioral changes that contribute to the progression and maintenance of addiction. However, attempts at generating pharmacological treatments for psychostimulant addiction have historically focused on intervening at the level of the acute effects of these drugs. The lack of approved pharmacological treatments for psychostimulant addiction highlights the need for new treatment strategies, especially those that prevent or ameliorate the adaptive neural, cognitive, and behavioral changes caused by chronic use of this class of illicit drugs.
\end{abstract}

Keywords: substance abuse, pharmacotherapy, cocaine, amphetamine, methamphetamine, addiction, human

\section{Introduction}

Drug addiction, also referred to as substance dependence, is a serious and chronically relapsing disease wherein the afflicted individual has difficulty limiting drug intake, exhibits high motivation to take the drug, continues using the drug despite negative consequences, and experiences negative emotional and physiological states when the drug is withheld. ${ }^{1}$ In the United States, the 2010 prevalence rates (current and pastmonth use, in persons aged 12 years or older) for illicit drug use (including marijuana, cocaine, and heroin) reached 22.6 million $(8.9 \%) .{ }^{2}$ The estimated number of persons aged 12 years or older classified with substance dependence (including illicit drugs and alcohol) in 2010 was 22.1 million, representing $8.7 \%$ of the US population. ${ }^{2}$ Furthermore, 20.5 million Americans were classified as needing treatment for an illicit drug or alcohol use problem. ${ }^{2}$ Of the 1 million persons that felt that they needed treatment for illicit drug or alcohol use problems, only 33\% made an effort to seek treatment. $^{2}$ These surprisingly high numbers and lack of effort to seek treatment clearly indicate that illicit drug addiction remains a significant problem in the US.

The most frequently abused illicit psychostimulants include cocaine and amphetamines, the latter of which represents a class of structurally related molecules, including D-amphetamine (AMPH), methamphetamine (METH), and 3,4-methylenedioxymethamphetamine (MDMA, commonly referred to as Ecstasy). 
Recent epidemiological data showed that in 2010 there were 1.5 million current cocaine users aged 12 or older, which comprised $0.6 \%$ of the population. ${ }^{2}$ The number of METH users represented $0.1 \%$ of the population, and the number of MDMA users was approximately $0.5 \%{ }^{2}$ In addition to the use of these classical illicit psychostimulants, the years 2010 and 2011 were characterized by a dramatic rise in the number of users of a newer class of amphetamine-like psychostimulants called synthetic cathinones, more frequently referred to as "bath salts". ${ }^{3}$ However, due to the very recent emergence of the use of synthetic cathinones, national epidemiological data on the prevalence of their use as well as long-term effects on the brain are not yet available.

Using both animal models of addiction as well as advanced neuroimaging techniques, researchers have identified various neural substrates of addiction to psychostimulants, with primary emphasis on the ability of addictive drugs to "hijack" the brain's natural reward circuitry. ${ }^{4}$ In recent years, it has become apparent that while acute psychostimulant use activates this reward circuitry, chronic drug use progressively "rewires" the brain and produces many lasting neuroadaptations that have been characterized as a pathology of "staged neuroplasticity." The present review will provide a general overview of the reward and addiction neurocircuitries, the initial subjective effects of illicit psychostimulants and their mechanisms of action, the neuropsychological, psychiatric, and neurological sequelae of chronic psychostimulant use in humans, and functional and structural changes in the neurocircuitry of addiction. Since MDMA and synthetic cathinones possess unique pharmacological and hallucinogenic properties, and their addictive potential is less well established, our review will focus on the traditional psychostimulants cocaine, AMPH, and METH. In light of the fact that no pharmacological treatment has yet been approved by the US Food and Drug Administration (FDA) specifically for psychostimulant dependence, we will also summarize the newer and more promising investigational treatments and approaches.

\section{Theories of addiction}

The transition from drug use to drug dependence is impacted by numerous factors, including genetics, environmental influences (such as stress and early life experiences), and neurochemical and neuroanatomical modifications in the brain that result from repeated drug use. ${ }^{6,7}$ Initial drug use can be attributed to the ability of the drug to act as a reward (ie, a pleasurable emotional state or positive reinforcer), which can lead to repeated drug use and dependence. ${ }^{8,9}$ A great deal of research has focused on the molecular and neuroanatomical mechanisms of the initial rewarding or reinforcing effect of drugs of abuse. However, more recent research on the long-term neuroanatomical and molecular changes in the brain that result from chronic drug use has revealed drug addiction to be highly complex and involve brain systems beyond the canonical reward circuitry.

Several parallel and intersecting theories of drug addiction include changes in behavior that are supported by various alterations in the underlying neurocircuitry of addiction. Robinson and Berridge hypothesized that repeated drug use produces alterations in the brain reward and associative learning systems, such that the drug user becomes increasingly sensitive to both the drug and drug-associated cues, resulting in pathological drug seeking or "wanting.", "10,11 Koob and Le Moal have postulated that repeated drug use and dependence are a result of decreased functioning of the brain's reward system coupled with an increase in the engagement of the brain's antireward or stress circuitries. ${ }^{12,13}$ These two opposing neurocircuitries are hypothesized to interact in a cyclical manner that ultimately manifests as addiction. ${ }^{12}$ Everitt and Robbins have theorized that drug addiction is the result of transitions from initial, voluntary drug use to habitual and eventually compulsive drug use, which results from a switch in the relative engagement of the neurocircuitries underlying these behaviors. ${ }^{14}$ Finally, Hyman and colleagues have also suggested has also suggested that addiction is a disorder characterized by the "hijacking" of normal learning and memory processes involved in reward seeking and drug-cue associations. ${ }^{4}$

These theories all agree that drug addiction is characterized by a progression or shift from initial stages, where the drug user is in control, to the end stages, where the drug user has lost control over drug use. Furthermore, this continuum of behavioral adaptation is proposed to be mediated by druginduced alterations in the neurocircuitries underlying reward, executive function, and learning and memory. Despite these recent advances in our understanding of the addicted brain, the majority of FDA-approved treatments for drug addiction aim to intervene at the level of the acute rewarding effects of drugs of abuse.

\section{The neurocircuitry of addiction}

The brain reward circuitry underlies all motivated behavior for natural rewards (eg, food, water, and sex) as well as drug rewards. Some of the key brain regions of the reward circuitry include the ventral tegmental area (VTA), nucleus accumbens (NAc), prefrontal cortex (PFC), basal ganglia, dorsal striatum (DS), amygdala (AMG), and hippocampus (HPC) (Figure 1). 


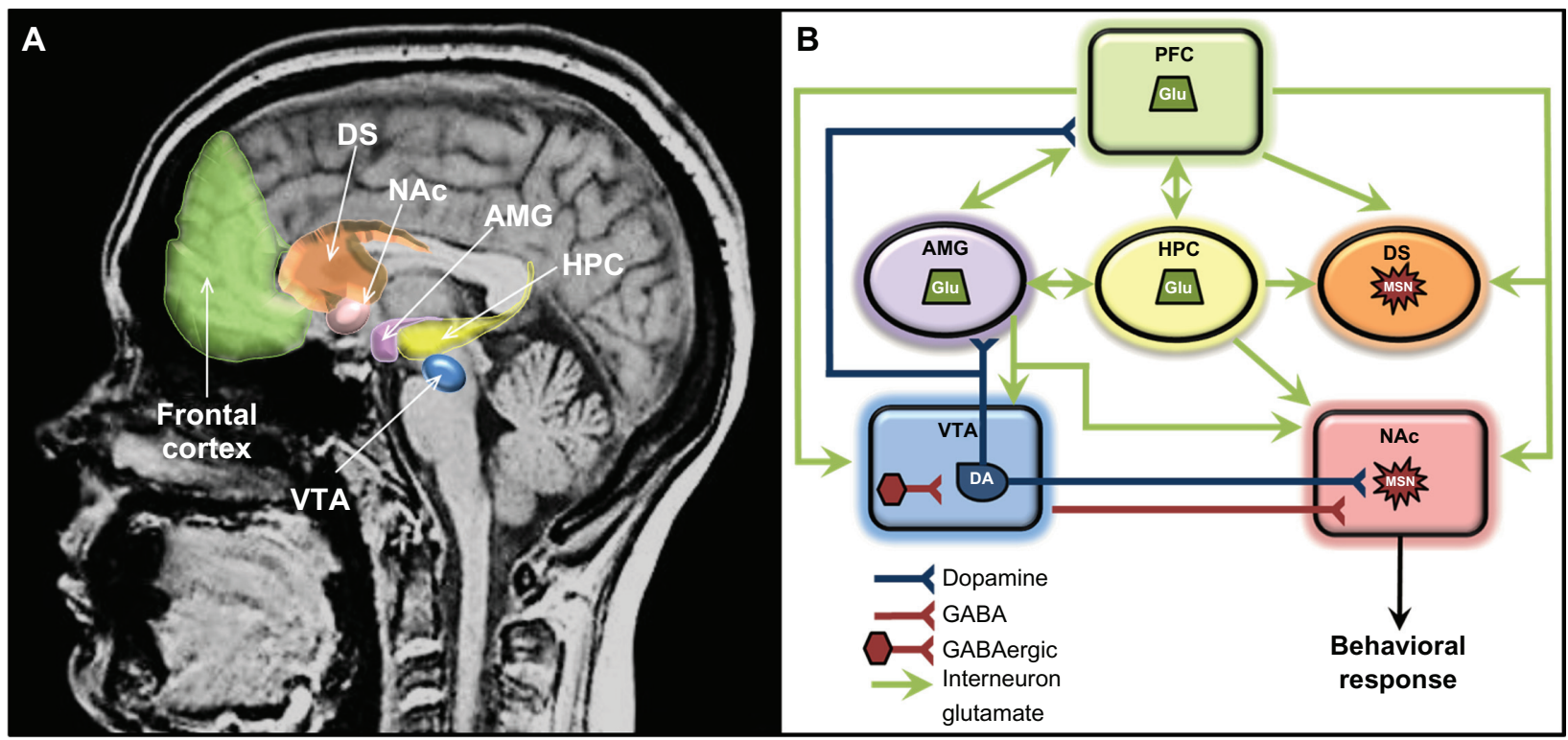

Figure I (A and B) Components of the principal reward neurocircuitries in the brain. (A) Neuroanatomical location of reward circuitry; (B) schematic of reward circuitry with primary neurotransmitter projections.

Note: Frontal cortex includes prefrontal, orbitofrontal, and anterior cingulate cortex.

Abbreviations: AMG, amygdala; DA, dopaminergic neurons; DS, dorsal striatum; GABA, $\gamma$-aminobutyric acid; Glu, glutamatergic neurons; HPC, hippocampus; MSN, medium spiny neurons; NAc, nucleus accumbens; PFC, prefrontal cortex; VTA, ventral tegmental area.

The rewarding effects of drugs and the progression from initial drug use to dependence are highly dependent on complex interactions between and adaptations within these regions. The key neurotransmitter that has been historically thought to mediate reward is dopamine (DA). However, as discussed below, psychostimulants also increase extracellular levels of glutamate (Glu), norepinephrine (NE), serotonin (5-HT), and other neurotransmitters within this neurocircuitry, which contribute to many of the long-term molecular and behavioral changes underlying addiction. ${ }^{15,16}$

\section{Reward systems}

Ventral tegmental area

The brain reward circuit functionally begins with the VTA, which contains a cluster of dopaminergic cells with efferent projections to the NAc and to other brain regions, such as the PFC and AMG. Many natural rewards and drugs of abuse activate the dopaminergic neurons of the VTA to release DA in these brain regions. ${ }^{10,17-20}$ The VTA is also modulated by glutamatergic inputs from the PFC and AMG, in addition to a subpopulation of inhibitory $\gamma$-aminobutyric acid (GABA), interneurons within the VTA. ${ }^{21}$ Recent evidence also suggests that inputs to the VTA containing the stressrelated peptide corticotropin releasing factor (CRF) may be responsible for modulating stress-induced influences on drug-seeking behavior, while orexin-containing inputs to the VTA from hypothalamic regions may also be involved in relapse-like behaviors. ${ }^{22,23}$ These neurotransmitter and neuropeptide interactions result in numerous cellular and molecular changes that contribute to reward-associated learning and the development of addiction. ${ }^{24}$

\section{Nucleus accumbens}

Most drugs of abuse, particularly psychostimulants, induce DA release at the level of the terminal fields in the NAc, PFC, and $\mathrm{AMG}^{25}$ The release of DA in the NAc appears to be crucial for the rewarding effects of drugs of abuse. The NAc, which is contained within the ventral striatum, is composed primarily of GABAergic medium spiny neurons (MSNs). The NAc can be functionally subdivided into two distinct subregions, the core and shell, which respond to rewarding stimuli differently and are thought to mediate distinct aspects of addictive processes. The release of DA in the NAc shell contributes to the initial rewarding and reinforcing effects of drugs and the assignment of salience to rewarding stimuli, whereas DA release in the NAc core is thought to be more associated with the expression of learned behaviors in response to rewarding stimuli, such as drug seeking. ${ }^{26-30}$ Drug-induced elevations in extracellular DA in the NAc and other brain regions of the reward circuitry are modulated by numerous other neurotransmitter systems, including GABA, Glu, endogenous opioids and cannabinoids, 5-HT, NE, and various neuropeptides such as CRF. ${ }^{15,16,25,31-33}$ Furthermore, these neurotransmitter systems 
can modulate psychostimulant intake and drug-seeking behavior. For example, various ionotropic and metabotropic glutamate receptors in both the NAc core and shell mediate context-induced reinstatement of cocaine seeking. ${ }^{34}$

\section{Executive function and habit systems} Prefrontal cortex

The PFC is a key regulator of cognitive and emotional processes, and contains many functionally distinct subregions. The dorsolateral PFC, orbitofrontal cortex (OFC), and anterior cingulate cortex are involved in salience attribution, decisionmaking, inhibition of inappropriate behaviors, behavioral and cognitive flexibility, and the regulation of emotion. ${ }^{35-37}$ These regions of the PFC have dense populations of glutamatergic cell bodies with efferent pathways that synapse onto the same cell populations (ie, MSNs) in the NAc that receive dopaminergic afferents from the VTA. ${ }^{38}$ In addition, glutamatergic efferents from the PFC also project to the AMG, VTA, DS, and indirectly to the HPC. ${ }^{39-41}$ Thus, the $\mathrm{PFC}$ is situated to modulate the rewarding effects of drugs of abuse and drug-seeking behavior, as well as relapse to drug taking. ${ }^{42}$ The PFC coordinates the flexibility with which an organism adapts its goal-directed behavior at many stages in the addiction process, and is modulated by inputs from other cortical and subcortical regions.

\section{Dorsal striatum and cortical-basal ganglia loops}

Regions of the basal ganglia, which include the dorsal and ventral striatum, internal and external segments of the globus pallidus, subthalamic nucleus, and dopaminergic cell bodies in the substantia nigra, are highly implicated not only in fine motor control but also in PFC function. ${ }^{43}$ Of these regions, the NAc (described above) and the DS (described below) are most frequently examined with respect to addiction. Thus, only a brief description of the modulatory role of the basal ganglia in addiction-relevant circuits will be mentioned here. The overall output of the basal ganglia is predominantly via the thalamus, which then projects back to the PFC to form cortico-striatal-thalamo-cortical (CSTC) loops. Three CSTC loops are proposed to modulate executive function, action selection, and behavioral inhibition. In the dorsolateral prefrontal circuit, the basal ganglia primarily modulate the identification and selection of goals, including rewards. ${ }^{44}$ The OFC circuit modulates decision-making and impulsivity, and the anterior cingulate circuit modulates the assessment of consequences. ${ }^{44}$ These circuits are modulated by dopaminergic inputs from the VTA to ultimately guide behaviors relevant to addiction, including the persistence and narrowing of the behavioral repertoire toward drug seeking, and continued drug use despite negative consequences. ${ }^{43-45}$

The DS (also referred to as the caudate-putamen in primates) is associated with transitions from goal-directed to habitual drug use, due in part to its role in stimulus-response learning. ${ }^{28,46}$ As described above, the initial rewarding and reinforcing effects of drugs of abuse are mediated by increases in extracellular DA in the NAc shell, and after continued drug use in the NAc core. ${ }^{47,48}$ After prolonged drug use, drug-associated cues produce increases in extracellular DA levels in the DS and not in the NAc. ${ }^{49}$ This lends to the notion that a shift in the relative engagement from the ventral to the dorsal striatum underlies the progression from initial, voluntary drug use to habitual and compulsive drug use. ${ }^{28}$ In addition to DA, recent evidence indicates that glutamatergic transmission in the DS is important for drug-induced adaptations and plasticity within the DS. ${ }^{50}$

\section{Learning and memory systems Hippocampus}

The HPC is highly involved in normal spatial memory function, in part due to its critical involvement in the integration of contextual and environmental cues or information. ${ }^{51}$ Interestingly, the ventral subiculum, the primary output of the HPC, projects to several limbic regions, including the NAc and DS. ${ }^{52}$ The ventral subiculum has been found to play a key role in cocaine-seeking behavior, suggesting the importance of contextual information in psychostimulant addiction. ${ }^{53}$ In addition, the ventral subiculum-to-NAc pathway has been implicated in psychostimulant sensitization in a DA-dependent manner. ${ }^{54,55}$ Recently, it was found that a trans-synaptic link between the CA3 region of the HPC and the VTA may also mediate the ability of contextual information to modulate motivational behaviors. ${ }^{56}$ Microinjection studies by Fuchs and colleagues have also demonstrated a role for Glu transmission in the dorsal HPC in context-induced cocaine-seeking. ${ }^{57}$

\section{Amygdala}

The AMG plays a prominent role in conditioned learning, wherein strong associations between environmental stimuli and the rewarding effects of drug use are made. Glutamatergic efferents from the AMG to the PFC, NAc, and HPC mediate behavioral responses to these stimuli. ${ }^{58-60}$ The AMG is composed of multiple nuclei that play distinct roles in addiction related associative learning. The stress neuropeptide CRF within the central nucleus of the AMG mediates various aspects of stress-motivated behaviors pertinent to addiction, 
and drug-induced adaptations in CRF signaling have been found to occur within the AMG. ${ }^{61,62}$ In addition, the basolateral AMG is critical for cue-induced relapse, while the central nucleus of the AMG is a key neural substrate underlying stress-induced relapse. ${ }^{63-66}$ The reciprocal connections between the basolateral AMG and the anterior cingulate cortex may be particularly important for cocaine cue-induced relapse. ${ }^{67,68}$ Interestingly, the AMG and ventral subiculum themselves have reciprocal connections and have been found to project to the same population of NAc neurons. ${ }^{69,70}$ Thus, the outputs of the AMG and HPC interact and converge to modulate the reward circuitry and potentially solidify reward-context and reward-cue associations that contribute to the chronic relapsing characteristics of addiction.

\section{Acute effects of psychostimulants Mechanisms of action}

As discussed above, a common neurobiological effect of many drugs of abuse is the direct or indirect modulation of DA-containing cell bodies in the VTA that target the NAc, resulting in the selective enhancement of extracellular DA levels in the NAc. ${ }^{20,72-74}$ However, not all drugs act directly on VTA dopaminergic neurons at the level of the cell bodies. Psychostimulants exert their effects through interactions with vesicular and plasma membrane monoamine reuptake transporters on presynaptic terminals in the NAc. ${ }^{75}$ Cocaine binds transporters for DA, NE, and 5-HT and competitively inhibits their function, resulting in increased extracellular levels of DA, NE, and 5-HT in the NAc. ${ }^{76}$ In transgenic mice lacking DA transporters (DATs), administration of cocaine did not result in enhanced locomotor activity or increased DA levels in the striatum, though these mice could learn to self-administer cocaine, potentially due to action at the NE and 5-HT transporters. ${ }^{77-79}$

Amphetamines (AMPH and METH) exert their effects in a more complex manner. Rather than simply blocking DATs (or NE and 5-HT transporters) to increase extracellular monoamine levels in the NAc, amphetamines function to reverse the transport function of DAT, resulting in increased extracellular levels of DA. The exact mechanism of this reversal remains unclear. ${ }^{80,81}$ As part of this effect on DAT, amphetamines are transported into the presynaptic terminal via DATs and accumulate within the cytosol. ${ }^{82}$ An additional mechanism of action for amphetamines is to cause the redistribution of monoamines from synaptic vesicles to the cytosol. ${ }^{83,84}$ Several mechanisms for this redistribution have been suggested. Two primary hypotheses are that amphetamines act as a substrate at the vesicular monoamine transporters (VMAT2 in neurons) or that they act as a weak base to collapse the vesicular $\mathrm{pH}$ gradient (see Rudnick and Clark $^{75}$ for review). Furthermore, amphetamines prolong monoaminergic transmission by inhibiting monoamine oxidase (MAO) activity and enhancing the activity of the rate-limiting DA synthetic enzyme tyrosine hydroxylase (TH) ${ }^{85-87}$ While NE and 5-HT levels also increase in the NAc as a result of stimulant use, increased extracellular DA plays a more prominent role in the initial rewarding and reinforcing properties of stimulants. ${ }^{78}$ Interestingly, AMPH and METH are reported to be more potent releasers of NE than DA, and much less potent at releasing $5-\mathrm{HT}^{89}$

\section{Subjective effects and pharmacokinetics}

Psychostimulants are associated with euphoria, increased self-confidence as well as increased energy, wakefulness and activity, with associated decreased fatigue and appetite..$^{90-93}$ Adrenergic (sympathetic nervous system) effects of these drugs include elevated heart and respiration rate, blood pressure, body temperature, and sweating, in addition to increased tremor and exaggeration of reflexes. ${ }^{90,92,94,95}$ While different classes of illicit psychostimulants exert largely similar subjective effects, they differ in their pharmacokinetic properties. Cocaine has a short half-life of 30 minutes to 2 hours, and the time to peak subjective effects differs by route of administration. ${ }^{96}$ When acidic cocaine (cocaine hydrochloride) is snorted, peak effects are felt within 10-15 minutes, while injection of acidic cocaine leads to peak effects within 3-4 minutes. ${ }^{97-99}$ Basic cocaine ("crack") can be smoked and is considered more addictive, primarily due to the rapid peak effects (1-2 minutes). ${ }^{97,98}$ METH can also be administered via several routes, including oral, intravenous, and smoked. ${ }^{99}$ As with cocaine, smoking METH leads to a more rapid "high," potentially contributing to increased addiction liability of this route of administration. ${ }^{100}$ METH has a much longer half-life (10-12 hours) compared to cocaine. ${ }^{101} \mathrm{AMPH}$ is primarily used via oral or intravenous routes and also has a longer half-life of 10-14 hours. ${ }^{99,102}$ Various AMPH salt mixtures, such as D-AMPH, L-AMPH, are also used in medications to treat attention deficit/hyperactivity disorder, and are often described and alternatively categorized as prescription drugs. It is commonly thought that METH is more addictive than AMPH, which is supported by the finding that METH may have a stronger effect on DAT-mediated cell physiology and DA clearance in the NAc, though METH and AMPH do not differ in other pharmacokinetic properties or in the magnitude of DA release in the DS. ${ }^{103,104}$ 


\section{Chronic effects of psychostimulants}

As previously described, drug addiction is considered a transitional process from casual drug use to habitual and uncontrolled drug use to dependence. Thus, different neurobiological adaptations likely underlie different stages of addiction. Several types of long-term changes can occur following prolonged drug use, including impairments in cognition and behavior, dysregulated functional connectivity within the brain, altered monoamine (primarily DA) receptor and transporter expression, and neurotransmitter synthesis and release. The focus of this section will be to provide a general picture of the long-term effects of chronic illicit psychostimulant use in humans. The majority of clinical research has focused on cocaine and METH users, with the frequent assumption that chronic AMPH use leads to similar outcomes as METH. Due to the variability in duration of drug abstinence in human subjects, the present review focuses on studies that utilized current psychostimulant users, or users in early stages of abstinence. For more detailed information on psychostimulant relapse, the reader is referred to several recently published reviews. ${ }^{105-107}$ In addition, a couple of caveats relevant to research on the chronic effects of psychostimulants in humans deserve to be mentioned. First, it is important to note that not every individual that experiences the acute effects of psychostimulants will become a chronic user. Individual predisposing factors, such as genetic vulnerabilities, trait impulsivity, socioeconomic status, early life experiences, and stress exposure, all significantly impact the addiction process. Secondly, only longitudinal studies in humans can truly determine whether the neuropsychological, psychiatric, or neuroanatomical differences in chronic psychostimulant users are a result of drug use or predisposing factors.

\section{Neuropsychological effects}

Chronic use of psychostimulants results in widespread impairments of neuropsychological functioning, including measures of memory, executive function, and mental flexibility. The primary brain regions mediating these cognitive impairments are the same as those implicated in the neurocircuitry of addiction, namely the PFC, AMG, HPC, and CSTC loops. Chronic cocaine users demonstrated impaired executive functions, including measures of attention, working memory, set-shifting, mental flexibility, and response inhibition. ${ }^{108}$ In one measure of PFC-mediated executive function, the Wisconsin Card Sorting Task, both METH-dependent subjects and chronic cocaine users demonstrated significant impairments (ie, increased perseverative responding). ${ }^{109-111}$ In addition, cocaine-dependent subjects exhibit poor performance on a delayed-discounting and reversal-learning task. ${ }^{112}$ In another study, chronic cocaine users, but not AMPH users, demonstrated increased perseverative responding in a probabilistic reversal-learning task. ${ }^{113}$

METH-dependent subjects also exhibit impaired global neuropsychological function, specifically in the domains of executive function, learning, motor ability, and speed of information processing. ${ }^{114}$ These impairments improved significantly following a period of abstinence. ${ }^{114}$ The same study found no effects of chronic METH use on measures of memory, working memory, or verbal abilities. ${ }^{114}$ However, other studies found that METH-dependent subjects exhibited impaired visual memory and executive control of verbal learning. ${ }^{115,116}$ Differences between these studies on the effects of METH on verbal processes and memory may be in part due to differing histories of METH use in METH-dependent subjects across studies. ${ }^{2,3}$ METH-dependent subjects were also impaired in measures of real-life skills, such as comprehension, finance, transportation, communication, and medication management. ${ }^{109}$ In addition, METH abusers demonstrated impaired social cognition, as measured by facial emotionrecognition tasks, especially with respect to fear recognition. ${ }^{111}$ Interestingly, impairments in executive function and social cognition have been found to be positively correlated. ${ }^{4,111,117} \mathrm{In}$ another study, METH-dependent subjects demonstrated slower reaction times and increased error and response-inhibition rates on a "go/no go" task. ${ }^{118}$ These performance deficits were more severe in the presence of cue-elicited craving. ${ }^{118}$

\section{Neurological and psychiatric effects}

Psychosis is a common effect of chronic psychostimulant abuse. Psychotic symptoms include both hallucinations and delusions. Lifetime use of cocaine, but not AMPH, is associated with the experience of psychotic symptoms after adjusting for demographic covariates, comorbidity, and childhood adversity. ${ }^{119}$ Severity of psychosis as a result of long-term psychostimulant abuse is increased in those that begin using at younger ages and use for longer periods of time. ${ }^{120}$ Interestingly, cocaine- and METH-dependent women are more likely than men to experience a variety of psychotic symptoms, including delusions of grandeur and tactile hallucinations. ${ }^{121}$ Chronic use of psychostimulants is also associated with various other psychiatric disorders, including mood and anxiety disorders. METH users are more likely than cocaine users to have a comorbid psychiatric diagnosis, such as major depression, bipolar disorder, and anxiety disorders. ${ }^{122} \mathrm{~A}$ separate study found that METH-dependent 
subjects reported increased depressive symptoms and acute affective distress compared to control subjects, and that these symptoms improved following a period of abstinence. ${ }^{114}$

A more unusual effect of chronic psychostimulant use is formication, the sensation of organisms crawling under one's skin, which has been reported by both chronic METH and cocaine users. ${ }^{94}$ These "meth mites" or "crank bugs" frequently lead to excessive skin picking, sores, and infections. ${ }^{123,124}$ Other neurological effects of chronic psychostimulant use include punding (engagement in purposeless and repetitive activities, such as assembling and disassembling electronics), grooming behaviors, and dyskinesias. ${ }^{125-127}$ With regard to the latter, choreoathetoid movements (involuntary and aimless movements; also known as "crack dancing") are associated with both AMPH and cocaine abuse. ${ }^{128}$ Interestingly, many of the neurological and psychiatric effects of chronic psychostimulant use, with the exception of altered mood and psychosis, are symptoms related to altered functioning in the striatal region of the basal ganglia and are likely a result of damage to dopaminergic terminals.

\section{Neurocircuitry: brain imaging} Functional effects

Chronic psychostimulant use is associated with alterations in functional connectivity, white- and gray-matter densities, and activation of distinct brain regions underlying reward and cognitive function. Connectivity and activation studies are conducted with various iterations of magnetic resonance imaging (MRI), while density studies utilize either MRI or diffusion tensor imaging. A greater number of studies have been conducted in cocaine-dependent individuals than AMPH or METH users. In a detailed study using restingstate functional MRI connectivity analysis with seed voxels, cocaine users exhibited decreased connectivity between (1) the VTA and the region encompassing the thalamus/ lentiform nucleus/NAc, (2) the $\mathrm{AMG}$ and $\mathrm{mPFC}$, and (3) between the HPC and dorsal mPFC. ${ }^{129}$ These changes in the neurocircuitry of the cocaine-addicted brain are consistent with maladaptive or impaired reward processing, learning, memory, and emotional regulation. ${ }^{129}$ Interestingly, connectivity between the NAc and cortical regions was not reduced, potentially lending credence to the role of habitual drug use in addiction, which is more tightly regulated by the DS. ${ }^{129}$ Several studies suggest that cocaine addiction results in altered engagement of frontoparietal networks during attentional tasks. ${ }^{130,131}$ Recently it was found that cocaine abusers exhibited reduced functional connectivity between the midbrain, where DA neurons are situated, and cortical and subcortical brain regions during an attentional Stroop task that tested the processing of drug and neutral words. ${ }^{132}$ Reduced activation in the right parietal cortex, a region involved in attention, during the two-back verbal working memory task was also found in cocaine-dependent males. ${ }^{133}$ In a study investigating the neural underpinnings of drug craving, chronic cocaine use was associated with enhanced reactivity to drug-associated cues, paralleled by enhanced connectivity between the left dorsolateral PFC and occipital cortex compared to healthy control subjects. ${ }^{134}$ In addition, the OFC was activated significantly more in cocaine users in response to cocaine cues, but not appetitive stimuli. ${ }^{134} \mathrm{It}$ has also been found that chronic cocaine users demonstrate impaired sensorimotor abilities that are accompanied by abnormal activity in the cortical and subcortical brain areas involved in motor control. ${ }^{135}$

\section{Structural effects}

Cocaine users have reduced subcortical gray-matter density which negatively correlates with impaired performance in psychomotor performance, recognition and working memory, and planning. ${ }^{136}$ Interestingly, in a study that included cocaine- and AMPH-dependent subjects, reduced gray-matter volume in the medial OFC was found, which correlated with increased high-risk decisions in a modified gambling task. ${ }^{137}$ Likewise, cocaine-dependent subjects demonstrated impaired decision-making on the Iowa gambling task, which correlated with compromised frontal, parietal, and corpus callosum white-matter integrity. ${ }^{138}$ In addition, abnormalities in white-matter microstructure underlying the PFC and HPC are associated with chronic METH use, during both late and early abstinence. ${ }^{139,140}$ Chronic METH use is also associated with gray-matter deficits in the cingulate and limbic cortices, reduced hippocampal volume, and white-matter hypertrophy in the temporal regions around the HPC. ${ }^{141}$ These cortical and hippocampal abnormalities likely contribute to impaired memory performance found in chronic METH users, while white-matter hypertrophy may be related to altered glial changes. ${ }^{141}$ Additionally, decreased temporal lobe, but not frontal lobe, volume was found in both AMPH- and cocaine-dependent subjects. ${ }^{142}$

\section{Effects on molecular substrates: DA receptors, DAT, and VMAT}

\section{Postmortem studies}

Repeated psychostimulant use can alter DA receptor and transporter expression in several brain regions. Most human postmortem studies have focused on DAT expression in 
cocaine-dependent subjects. The majority of these studies, which used either saturation-binding or autoradiography techniques, demonstrated increased DAT binding in the striatum of cocaine-dependent subjects compared to control subjects (see Table 1 in Rajesh and Diana). ${ }^{143}$ However, others have found decreased DAT-binding sites in the postmortem PFC from chronic cocaine users compared to non-cocaineusing controls. ${ }^{144}$ In the postmortem striatum of METH users, decreased TH immunoreactivity and DAT levels were found. ${ }^{145}$ In a subset of individuals, VMAT2 levels were also significantly reduced, though this were not common. ${ }^{145}$ Another postmortem study in chronic METH users found decreased levels of DA, TH, and DAT in the striatum, but normal levels of L-3,4-dihydroxyphenylalanine (DOPA) decarboxylase (the enzyme that converts L-DOPA into DA) and VMAT2. ${ }^{146}$ The authors concluded that chronic METH use does not cause permanent degeneration of striatal DA nerve terminals. Postmortem studies of VMAT2 expression in the striatum of cocaine abusers have had mixed results, with two studies finding decreased VMAT2 and one study finding no change. ${ }^{147-149}$

\section{Imaging studies}

Imaging studies of receptor and transporter expression are typically conducted with positron-emission tomography (PET). Imaging studies, while sacrificing spatial resolution, avoid some of the limitations of postmortem studies, such as antemortem tissue events, varied time since death, and undocumented life-history events. The majority of these types of studies have again focused on the availability of DA receptors and transporters and VMAT2, as well as DA uptake and synthesis. In chronic cocaine abusers, VMAT2 availability was decreased in the NAc (referred to as the ventral striatum) and DS (referred to as the associative and sensorimotor striatum) compared to control subjects. ${ }^{150}$ This may reflect potential compensatory downregulation in response to loss of DA terminals. ${ }^{150}$ Stimulant-induced DA release, as measured by displacement

Table I Summary of acute and chronic effects of psychostimulants in humans

\begin{tabular}{|c|c|c|}
\hline Acute effects & Cocaine & METH/AMPH \\
\hline Primary site of action & Presynaptic monoaminergic terminals in NAc. & Presynaptic monoaminergic terminals in NAc. \\
\hline \multirow[t]{2}{*}{ Mechanism of action } & Inhibition of DA, NE and 5-HT transporters. & Reverse DA, NE, 5-HT transporter function. \\
\hline & & Redistribution monoamines to cytosol via VMAT2. \\
\hline Half-life & 30 minutes -2 hours. & $10-14$ hours. \\
\hline Subjective effects & \multicolumn{2}{|c|}{$\begin{array}{l}\text { Euphoria, increased libido and self-confidence. Increased energy, wakefulness and activity. Decreased appetite anc } \\
\text { fatigue. }\end{array}$} \\
\hline Adrenergic effects & \multicolumn{2}{|c|}{$\begin{array}{l}\text { Elevated heart rate, blood pressure and rapid breathing. Elevated body temperature and sweating. Tremor anc } \\
\text { exaggeration of reflexes. }\end{array}$} \\
\hline \multicolumn{3}{|l|}{ Chronic effects } \\
\hline Neuropsychological & \multicolumn{2}{|c|}{$\begin{array}{l}\text { Impaired executive function, learning, mental flexibility. Impaired motor abilities and reaction time. Impaired information } \\
\text { processing and social cognition. }\end{array}$} \\
\hline Psychiatric and Neurological & \multicolumn{2}{|c|}{$\begin{array}{l}\text { Psychosis, comorbid psychiatric disorders such as depression and anxiety. Formication (skin picking at "METr } \\
\text { mites" or "crank bugs"), punding (purposeless and stereotyped behavior) and choreoathetoid (twisting and aimless } \\
\text { movements. }\end{array}$} \\
\hline Neurocircuitry & \multicolumn{2}{|c|}{$\begin{array}{l}\text { Decreased functional connectivity and activation within the reward circuitry and cortical and subcortical region } \\
\text { mediating executive function, learning and memory. Reduced subcortical gray matter. Reduced integrity anc } \\
\text { abnormalities in white matter in the HPC, PFC and other cortical regions. }\end{array}$} \\
\hline Molecular substrates & Majority find increased striatal DAT. & Decreased striatal DA, DAT and TH levels. \\
\hline \multirow[t]{2}{*}{ Post-mortem } & \multirow[t]{2}{*}{ No consensus on striatal VMAT2. } & Normal striatal VMAT2 levels. \\
\hline & & Increased number of microglia in the striatum. \\
\hline Molecular substrates & Decreased striatal VMAT2 availability. & Increased striatal VMAT2, abstinence-dependent. \\
\hline \multirow[t]{2}{*}{ Imaging } & Blunting of striatal DA system function. & Decreased DAT in the striatum, PFC, and AMG. \\
\hline & \multicolumn{2}{|l|}{ Decreased striatal D2 receptor availability. } \\
\hline
\end{tabular}

Note: See text for citations, more detailed descriptions, and discrepancies.

Abbreviations: AMG, amygdala; AMPH, D-amphetamine; DA, dopamine; DAT, dopamine transporter; HPC, hippocampus; METH, methamphetamine; NAc, nucleus accumbens; NE, norepinephrine; PFC, prefrontal cortex; VMAT2, vesicular monoamine transporter 2; 5-HT, 5-hydroxytryptamine (serotonin). 
of DA receptor-antagonist radiotracers, was decreased in the striatum of cocaine-dependent subjects with 2-6 weeks of abstinence, indicating a blunting of striatal DA system function as a result of chronic cocaine use. ${ }^{151,152}$ PET studies have also found a significant decrease in striatal DA synthesis, as measured by $\left[{ }^{18} \mathrm{~F}\right] 6$-FDOPA uptake, in cocaine-dependent subjects. However, this was only evident in subjects that had been abstinent for greater than 10 days. ${ }^{153}$ Decreased striatal $\mathrm{D}_{2}$ receptor availability was also found in both cocaine- and METH-dependent subjects. ${ }^{152,154-156}$

In METH users, striatal VMAT2 binding was significantly increased with decreasing duration of abstinence (ie, 3 vs 21 days). ${ }^{157}$ These findings are in opposition to the slight increase in striatal VMAT2 binding found in METH abusers after long-term abstinence (ie, years). ${ }^{158}$ The disparity between these findings suggests that the time since last drug use is a critical variable that must be accounted for and controlled for in human studies. Most studies in METH-dependent subjects use currently abstinent subjects, but in those that were abstinent for an average of 6 months, decreased DAT was found in the DS (referred to as the caudate and putamen), NAc, PFC, OFC, and AMG. ${ }^{159-161}$ Unlike with VMAT2, increased duration of abstinence was associated with increased striatal DAT density. ${ }^{162}$

\section{Note on inflammatory effects}

Repeated use of high doses of METH results in neurotoxicity in preclinical models, particularly in the striatum (for review, see Krasnova and Cadet). ${ }^{163}$ While the mechanism underlying METH-induced neurotoxicity has not been fully elucidated, it is likely due to repeated, high levels of extracellular DA leading to production of quinones and free radicals such as reactive oxygen species. ${ }^{164,165}$ Studies in humans have investigated the role of inflammatory mediators in METHinduced neurotoxicity, due to the fact that microglial activation has been associated with METH neurotoxicity in animal models. ${ }^{166}$ Interestingly, the number of microglia but not activation of glial cells in the postmortem striatum of METH users was significantly increased. ${ }^{145}$ A follow-up study confirmed and extended these results in non-abstinent METH users, finding that METH use results in significantly increased striatal microglia in the absence of reactive gliosis. ${ }^{167}$ However, in abstinent METH abusers, a PET study found a significant increase in binding of a radiotracer (PK11195) for activated microglia in all brain regions. ${ }^{168}$ In adults in remission from METH dependence, immunesystem dysregulation was found, in addition to significant cognitive impairments, which encompassed learning, memory, and attentional/informational processing. ${ }^{169}$ In the same study, impaired global cognition was significantly and positively correlated with plasma levels of the cytokine alphainterferon. ${ }^{169}$ In addition, a decrease in the anti-inflammatory marker interleukin 10 and increased proinflammatory tumor necrosis factor alpha in response to stress exposure has been found in cocaine abusers (compared to social drinkers), potentially indicating an elevated inflammatory state. ${ }^{170}$ Interestingly, postmortem brain studies suggest that cocaine addiction is not associated with increased activation of markers of apoptotic cell-death pathways. ${ }^{47,171}$ Together, these initial studies indicate dysregulated inflammatory processes following chronic psychostimulant use in humans and provide evidence to support the need for further investigations.

\section{Implications for the treatment of substance abuse}

At present, no pharmacological therapy has been approved by the FDA to treat psychostimulant addiction. Many drugs have been tested, but none have shown conclusive efficacy with tolerable side effects in humans. ${ }^{172}$ These drugs have included DA-receptor ligands, such as DA receptor agonists, partial agonists, and antagonists, as well as DA-reuptake inhibitors. ${ }^{173,174}$ One newer dopaminergic drug that has shown some promise is the antipsychotic medication aripiprazole, a partial agonist at $\mathrm{D}_{2}$-like receptors, which is currently approved for the treatment of schizophrenia, depression, and bipolar disorder. ${ }^{175} \mathrm{Clinical}$ trials have thus far been mixed, with one study finding reduced cocaine craving and use, and another study showing increased cocaine use. ${ }^{176,177}$

Recent evidence for dysregulation of glutamatergic signaling in addiction has led to the testing of $N$-acetylcysteine, a derivative of the amino acid cysteine that normalizes extracellular levels of Glu following cocaine administration. ${ }^{178,179}$ Clinical trials found that $\mathrm{N}$-acetylcysteine treatment attenuates cocaine craving and use and normalizes brain glutamate levels. ${ }^{180-182}$ Other recent studies found trends toward significant reductions in METH use and craving produced by the antidepressant buproprion and the anticonvulsant topiramate, which has glutamate release-inhibiting properties. ${ }^{183,184}$ While these compounds have not demonstrated overwhelming efficacy in reducing psychostimulant use or craving in all subjects tested, trends toward effects were observed and thus merit further investigation.

Other compounds that have been tested, with disappointing results, include $\beta$-adrenergic antagonists, 
opioid-receptor antagonists, 5- $\mathrm{HT}_{3}$-receptor antagonists, antidepressants, and anticonvulsants. ${ }^{172,185-190}$ Despite the lack of past successes, several newer medications are currently being investigated and have shown some initial success, such as the smoking-cessation aid varenicline, the $\alpha_{2}$ adrenergic agonist clonidine, and the antidepressant mirtazapine. ${ }^{191-194}$ In addition, preclinical evidence strongly suggests potential therapeutic effects of compounds targeting receptors for endocannabinoids, the neuropeptide orexin, and CRF for the prevention of relapse to psychostimulant use. ${ }^{195-197}$

Future approaches for the treatment of psychostimulantinduced cognitive deficits and dependence include the use of cognitive enhancers. ${ }^{198-200}$ Two promising examples include prescription stimulants, such as modafinil and methylphenidate, which have shown modest but potential treatment effects in METH users and cocaine users with comorbid attention deficit/hyperactivity disorder, respectively. ${ }^{201-205}$ In addition, galantamine, a cholinergic modulator and cognitive enhancer, has been reported to both decrease cocaine use and improve sustained attention in dependent subjects. ${ }^{206,207}$ Together, these studies indicate that clinical trials of cognitive enhancers in the treatment of psychostimulant addiction are warranted.

In addition to the pharmacological trials reviewed above, less conventional strategies that are gaining scientific momentum include vaccine therapies to immunoneutralize drug molecules and impede penetrance across the bloodbrain barrier, enzyme conjugates that dramatically increase the metabolic breakdown of abused drugs, pharmacogenetic approaches based on individual genetic polymorphisms in addiction-related genes, and epigenetic modulators of druginduced changes in gene expression. ${ }^{208-211}$ While still in their relative infancy, these exciting new avenues of research offer a significant expansion of possible biologically based targets for the treatment of psychostimulant addiction.

\section{Conclusion}

Even with over half a century of research directed at understanding the mechanisms and treatment of psychostimulant addiction, this disorder remains a serious socioeconomic problem. Psychostimulants exert their acute rewarding and reinforcing actions primarily via direct and indirect release of extracellular DA in the NAc. DA release in other brain regions, such as the PFC and AMG, play a role in behavioral control and learned associations between environmental stimuli and the subjective rewarding effects. In addition to DA release, psychostimulants also alter other neurotransmitter systems, such as 5-HT, NE, Glu, endocannabinoids, and various neuropeptides. With continued drug use, other regions, such as the DS and CSTC, may mediate such behaviors as action control and habitual or compulsive drug seeking. Chronic drug use leads to persistent adaptive changes within the reward circuitry, including altered receptor and transporter expression, neurotransmitter release, and functional connectivity between brain regions. Ultimately, these adaptive changes are associated with an impaired cognitive state and neuropsychiatric symptoms. While some of the effects of chronic psychostimulant use may dissipate with increasing abstinence, many chronic users are unable to achieve or maintain even a short period of abstinence.

The tremendous need for more effective pharmacological treatments for psychostimulant addiction is a mainstay of contemporary addiction research. However, the recent downsizing of many major pharmaceutical companies away from psychiatric indications (including addiction) due to the lack of efficacy of experimental compounds in humans may require a sea change in the translational research approach. ${ }^{212,213}$ A new emphasis on larger-scale biomarker, genetic, and epigenetic research focused on the molecular targets of mental disorders has been recently advocated. ${ }^{212}$ In addition, the integration of cognitive and behavioral modification of circuit-wide neuroplasticity (ie, computerbased training to enhance executive function) may prove to be an effective adjunct-treatment approach for addiction, particularly when combined with cognitive enhancers. ${ }^{198,213-216}$ Furthermore, in order to be effective, all pharmacological or biologically based treatments for addiction need to be integrated into other established forms of addiction rehabilitation, such as cognitive behavioral therapy, individual and group psychotherapy, behavior-modification strategies, twelve-step programs, and residential treatment facilities.

\section{Acknowledgment}

The authors wish to acknowledge the support of NIH grants DA024355 and DA025606.

\section{Disclosure}

The authors report no conflicts of interest in this work.

\section{References}

1. American Psychiatric Association. Diagnostic and Statistical Manual of Mental Disorders, 4th ed, revised. Washington: American Psychiatric Association; 2000.

2. Substance Abuse and Mental Health Services Administration (SAMHSA). Results from the 2010 National Survey on Drug Use and Health: Summary of National Findings. Rockville (MD): SAMHSA; 2011. 
3. Fass JA, Fass AD, Garcia AS. Synthetic cathinones (bath salts): legal status and patterns of abuse. Ann Pharmacother. 2012;46(3):436-441.

4. Hyman SE. Addiction: A disease of learning and memory. Am J Psychiatry. 2005;162(8):1414-1422.

5. Kalivas PW, O'Brien C. Drug addiction as a pathology of staged neuroplasticity. Neuropsychopharmacology. 2007;33(1):166-180.

6. Li CY, Zhou WZ, Zhang PW, Johnson C, Wei L, Uhl GR. Meta-analysis and genome-wide interpretation of genetic susceptibility to drug addiction. BMC Genomics. 2011;12:508.

7. Sinha R. Chronic stress, drug use, and vulnerability to addiction. Ann NY Acad Sci. 2008;1141:105-130.

8. Wise RA. Action of drugs of abuse on brain reward systems. Pharmacol Biochem Behav. 1980;13 Suppl 1:213-223.

9. Stolerman I. Drugs of abuse: behavioural principles, methods and terms. Trends Pharmacol Sci. 1992;13(5):170-176.

10. Robinson TE, Berridge KC. The neural basis of drug craving: an incentive-sensitization theory of addiction. Brain Res Brain Res Rev. 1993;18(3):247-291

11. Berridge $\mathrm{KC}$, Robinson TE. The mind of an addicted brain: neural sensitization of wanting versus liking. Curr Dir Psychol Sci. 1995;4(3): $71-76$.

12. Koob GF, Le Moal M. Addiction and the brain antireward system. Annu Rev Psychol. 2008;59:29-53.

13. Koob GF, Le Moal M. Drug abuse: hedonic homeostatic dysregulation. Science. 1997;278(5335):52-58.

14. Everitt BJ, Robbins TW. Neural systems of reinforcement for drug addiction: from actions to habits to compulsion. Nat Neurosci. 2005;8(11):1481-1489.

15. Kalivas PW. The glutamate homeostasis hypothesis of addiction. Nat Rev Neurosci. 2009;10(8):561-572.

16. Hyman SE, Malenka RC. Addiction and the brain: the neurobiology of compulsion and its persistence. Nat Rev Neurosci. 2001;2(10):695-703.

17. McClure SM, Daw ND, Montague PR. A computational substrate for incentive salience. Trends Neurosci. 2003;26(8):423-428.

18. Berridge $\mathrm{KC}$, Robinson TE. What is the role of dopamine in reward: hedonic impact, reward learning, or incentive salience? Brain Res Brain Res Rev. 1998;28(3):309-369.

19. Taber MT, Fibiger HC. Feeding-evoked dopamine release in the nucleus, accumbens: regulation by glutamatergic mechanisms Neuroscience. 1997;76(4):1105-1112.

20. Di Chiara G, Imperato A. Drugs abused by humans preferentially increase synaptic dopamine concentrations in the mesolimbic system of freely moving rats. Proc Natl Acad Sci U S A. 1988;85(14): 5274-5278.

21. Johnson SW, North RA. Two types of neurone in the rat ventral tegmental area and their synaptic inputs. $J$ Physiol. 1992;450:455-468.

22. Mahler SV, Smith RJ, Aston-Jones G. Interactions between vta orexin and glutamate in cue-induced reinstatement of cocaine seeking in rats. Psychopharmacology (Berl). Epub March 13, 2012.

23. Wang B, Shaham Y, Zitzman D, Azari S, Wise RA, You ZB. Cocaine experience establishes control of midbrain glutamate and dopamine by corticotropin-releasing factor: a role in stress-induced relapse to drug seeking. J Neurosci. 2005;25(22):5389-5396.

24. Jay TM. Dopamine: a potential substrate for synaptic plasticity and memory mechanisms. Prog Neurobiol. 2003;69(6):375-390.

25. Koob GF, Volkow ND. Neurocircuitry of addiction. Neuropsychopharmacology. 2010;35(1):217-238.

26. Sellings LHL, Clarke PBS. Segregation of amphetamine reward and locomotor stimulation between nucleus accumbens medial shell and core. J Neurosci. 2003;23(15):6295-6303.

27. Bassareo V, Di Chiara G. Differential responsiveness of dopamine transmission to food-stimuli in nucleus accumbens shell/core compartments. Neuroscience. 1999;89(3):637-641.

28. Everitt BJ, Belin D, Economidou D, Pelloux Y, Dalley JW, Robbins TW. Review. Neural mechanisms underlying the vulnerability to develop compulsive drug-seeking habits and addiction. Philos Trans R Soc Lond B Biol Sci. 2008;363(1507):3125-3135.
29. Kelley AE. Ventral striatal control of appetitive motivation: role in ingestive behavior and reward-related learning. Neurosci Biobehav Rev. 2004;27(8):765-776.

30. Di Ciano P, Everitt BJ. Dissociable effects of antagonism of NMDA and AMPA/KA receptors in the nucleus accumbens core and shell on cocaineseeking behavior. Neuropsychopharmacology. 2001;25(3):341-360.

31. Serrano A, Parsons LH. Endocannabinoid influence in drug reinforcement, dependence and addiction-related behaviors. Pharmacol Ther. 2011;132(3):215-241.

32. Nichols DE. Differences between the mechanism of action of MDMA, $\mathrm{MBDB}$, and the classic hallucinogens. Identification of a new therapeutic class: entactogens. J Psychoactive Drugs. 1986;18(4):305-313.

33. Koob GF. Neural mechanisms of drug reinforcement. Ann N Y Acad Sci. 1992;654:171-191.

34. Xie X, Lasseter HC, Ramirez DR, Ponds KL, Wells AM, Fuchs RA. Subregion-specific role of glutamate receptors in the nucleus accumbens on drug context-induced reinstatement of cocaine-seeking behavior in rats. Addict Biol. 2012;17(2):287-299.

35. Volkow ND, Wang GJ, Fowler JS, Tomasi D, Telang F. Addiction: beyond dopamine reward circuitry. Proc Natl Acad Sci U S A. 2011; 108(37):15037-15042.

36. Breiter HC, Gollub RL, Weisskoff RM, et al. Acute effects of cocaine on human brain activity and emotion. Neuron. 1997;19(3):591-611.

37. Bush G, Vogt BA, Holmes J, et al. Dorsal anterior cingulate cortex: a role in reward-based decision making. Proc Natl Acad Sci U S A. 2002;99(1):523-528.

38. Sesack SR, Pickel VM. Prefrontal cortical efferents in the rat synapse on unlabeled neuronal targets of catecholamine terminals in the nucleus accumbens septi and on dopamine neurons in the ventral tegmental area J Comp Neurol. 1992;320(2):145-160.

39. Kalivas PW, Volkow ND. The neural basis of addiction: a pathology of motivation and choice. Am J Psychiatry. 2005;162(8):1403-1413.

40. Sesack SR, Deutch AY, Roth RH, Bunney BS. Topographical organization of the efferent projections of the medial prefrontal cortex in the rat: an anterograde tract-tracing study with phaseolus vulgaris leucoagglutinin. J Comp Neurol. 1989;290(2):213-242.

41. Vertes RP, Hoover WB, Szigeti-Buck K, Leranth C. Nucleus reuniens of the midline thalamus: link between the medial prefrontal cortex and the hippocampus. Brain Res Bull. 2007;71(6):601-609.

42. Lasseter HC, Xie X, Ramirez DR, Fuchs RA. Prefrontal cortical regulation of drug seeking in animal models of drug relapse. Curr Top Behav Neurosci. 2010;3:101-117.

43. Kopell BH, Greenberg BD. Anatomy and physiology of the basal ganglia: implications for DBS in psychiatry. Neurosci Biobehav Rev. 2008;32(3):408-422.

44. Feil J, Sheppard D, Fitzgerald PB, Yucel M, Lubman DI, Bradshaw JL. Addiction, compulsive drug seeking, and the role of frontostriatal mechanisms in regulating inhibitory control. Neurosci Biobehav Rev. 2010;35(2):248-275.

45. Sesack SR, Carr DB, Omelchenko N, Pinto A. Anatomical substrates for glutamate-dopamine interactions: evidence for specificity of connections and extrasynaptic actions. Ann NY Acad Sci. 2003;1003:36-52.

46. Yin HH, Knowlton BJ, Balleine BW. Lesions of dorsolateral striatum preserve outcome expectancy but disrupt habit formation in instrumental learning. Eur J Neurosci. 2004;19(1):181-189.

47. Di Chiara G, Bassareo V, Fenu S, et al. Dopamine and drug addiction: the nucleus accumbens shell connection. Neuropharmacology. 2004;47 Suppl 1:227-241

48. Ito R, Robbins TW, Everitt BJ. Differential control over cocaineseeking behavior by nucleus accumbens core and shell. Nat Neurosci. 2004;7(4):389-397.

49. Ito R, Dalley JW, Robbins TW, Everitt BJ. Dopamine release in the dorsal striatum during cocaine-seeking behavior under the control of a drug-associated cue. J Neurosci. 2002;22(14):6247-6253.

50. Grueter BA, Rothwell PE, Malenka RC. Integrating synaptic plasticity and striatal circuit function in addiction. Curr Opin Neurobiol. 2012; 22(3):545-551. 
51. Jarrard LE. What does the hippocampus really do? Behav Brain Res. 1995;71(1-2):1-10.

52. Groenewegen HJ, Vermeulen-Van der Zee E, te Kortschot A, Witter MP. Organization of the projections from the subiculum to the ventral striatum in the rat. A study using anterograde transport of phaseolus vulgaris leucoagglutinin. Neuroscience. 1987;23(1):103-120.

53. Sun W, Rebec GV. Lidocaine inactivation of ventral subiculum attenuates cocaine-seeking behavior in rats. $J$ Neurosci. 2003;23(32): 10258-10264.

54. Goto Y, Grace AA. Dopamine-dependent interactions between limbic and prefrontal cortical plasticity in the nucleus accumbens: disruption by cocaine sensitization. Neuron. 2005;47(2):255-266.

55. Lodge DJ, Grace AA. Amphetamine activation of hippocampal drive of mesolimbic dopamine neurons: a mechanism of behavioral sensitization. J Neurosci. 2008;28(31):7876-7882.

56. Luo AH, Tahsili-Fahadan P, Wise RA, Lupica CR, Aston-Jones G. Linking context with reward: a functional circuit from hippocampal CA3 to ventral tegmental area. Science. 2011;333(6040):353-357.

57. Xie X, Ramirez DR, Lasseter HC, Fuchs RA. Effects of mGluR1 antagonism in the dorsal hippocampus on drug context-induced reinstatement of cocaine-seeking behavior in rats. Psychopharmacology (Berl). 2010;208(1):1-11.

58. Cardinal RN, Parkinson JA, Hall J, Everitt BJ. Emotion and motivation: the role of the amygdala, ventral striatum, and prefrontal cortex. Neurosci Biobehav Rev. 2002;26(3):321-352.

59. Petrovich GD, Canteras NS, Swanson LW. Combinatorial amygdalar inputs to hippocampal domains and hypothalamic behavior systems. Brain Res Rev. 2001;38(1-2):247-289.

60. McGaugh JL. Memory consolidation and the amygdala: a systems perspective. Trends Neurosci. 2002;25(9):456-461.

61. Koob GF. The role of CRF and CRF-related peptides in the dark side of addiction. Brain Res. 2010;1314:3-14.

62. Zorrilla EP, Wee S, Zhao Y, et al. Extended access cocaine selfadministration differentially activates dorsal raphe and amygdala corticotropin-releasing factor systems in rats. Addict Biol. 2012;17(2): 300-308.

63. Everitt BJ, Morris KA, O'Brien A, Robbins TW. The basolateral amygdala-ventral striatal system and conditioned place preference: further evidence of limbic-striatal interactions underlying reward-related processes. Neuroscience. 1991;42(1):1-18.

64. Everitt BJ, Wolf ME. Psychomotor stimulant addiction: a neural systems perspective. J Neurosci. 2002;22(9):3312-3320.

65. Shalev U, Grimm JW, Shaham Y. Neurobiology of relapse to heroin and cocaine seeking: a review. Pharmacol Rev. 2002;54(1):1-42.

66. Shaham Y, Shalev U, Lu L, De Wit H, Stewart J. The reinstatement model of drug relapse: history, methodology and major findings. Psychopharmacology (Berl). 2003;168(1-2):3-20.

67. Kilts CD, Schweitzer JB, Quinn CK, et al. Neural activity related to drug craving in cocaine addiction. Arch Gen Psychiatry. 2001;58(4): 334-341.

68. Childress AR, Mozley PD, McElgin W, Fitzgerald J, Reivich M, O'Brien CP. Limbic activation during cue-induced cocaine craving. Am J Psychiatry. 1999;156(1):11-18.

69. French SJ, Totterdell S. Individual nucleus accumbens-projection neurons receive both basolateral amygdala and ventral subicular afferents in rats. Neuroscience. 2003;119(1):19-31.

70. French SJ, Hailstone JC, Totterdell S. Basolateral amygdala efferents to the ventral subiculum preferentially innervate pyramidal cell dendritic spines. Brain Res. 2003;981(1-2):160-167.

71. Wise RA. Dopamine and reward: The anhedonia hypothesis 30 years on. Neurotox Res. 2008;14(2-3):169-183.

72. Wise RA, Rompre PP. Brain dopamine and reward. Annu Rev Psychol. 1989;40:191-225.

73. Robinson TE, Becker JB. Enduring changes in brain and behavior produced by chronic amphetamine administration: a review and evaluation of animal models of amphetamine psychosis. Brain Res. 1986;396(2):157-198.
74. Berke JD, Hyman SE. Addiction, dopamine, and the molecular mechanisms of memory. Neuron. 2000;25(3):515-532.

75. Rudnick G, Clark J. From synapse to vesicle: the reuptake and storage of biogenic amine neurotransmitters. Biochim Biophys Acta. 1993;1144(3): 249-263.

76. Ritz MC, Cone EJ, Kuhar MJ. Cocaine inhibition of ligand binding at dopamine, norepinephrine and serotonin transporters: a structure-activity study. Life Sci. 1990;46(9):635-645.

77. Giros B, Jaber M, Jones SR, Wightman RM, Caron MG. Hyperlocomotion and indifference to cocaine and amphetamine in mice lacking the dopamine transporter. Nature. 1996;379(6566): 606-612.

78. Rocha BA. Stimulant and reinforcing effects of cocaine in monoamine transporter knockout mice. Eur J Pharmacol. 2003;479(1-3): 107-115.

79. Rocha BA, Fumagalli F, Gainetdinov RR, et al. Cocaine selfadministration in dopamine-transporter knockout mice. Nat Neurosci. 1998;1(2):132-137.

80. Sulzer D. How addictive drugs disrupt presynaptic dopamine neurotransmission. Neuron. 2011;69(4):628-649.

81. Sulzer D, Sonders MS, Poulsen NW, Galli A. Mechanisms of neurotransmitter release by amphetamines: a review. Prog Neurobiol. 2005;75(6):406-433.

82. Zaczek R, Culp S, De Souza EB. Interactions of [3H]amphetamine with rat brain synaptosomes. II. Active transport. J Pharmacol Exp Ther. 1991;257(2):830-835.

83. Jones SR, Gainetdinov RR, Wightman RM, Caron MG. Mechanisms of amphetamine action revealed in mice lacking the dopamine transporter. J Neurosci. 1998;18(6):1979-1986.

84. Sulzer D, Chen TK, Lau YY, Kristensen H, Rayport S, Ewing A. Amphetamine redistributes dopamine from synaptic vesicles to the cytosol and promotes reverse transport. $J$ Neurosci. 1995;15(5 Pt 2): 4102-4108.

85. Robinson JB. Stereoselectivity and isoenzyme selectivity of monoamine oxidase inhibitors. Enantiomers of amphetamine, $\mathrm{N}$-methylamphetamine and deprenyl. Biochem Pharmacol. 1985;34(23):4105-4108.

86. Fung YK, Uretsky NJ. The importance of calcium in the amphetamineinduced stimulation of dopamine synthesis in mouse striata in vivo. J Pharmacol Exp Ther. 1982;223(2):477-482.

87. Larsen KE, Fon EA, Hastings TG, Edwards RH, Sulzer D. Methamphetamine-induced degeneration of dopaminergic neurons involves autophagy and upregulation of dopamine synthesis. J Neurosci. 2002;22(20):8951-8960.

88. Espana RA, Jones SR. Presynaptic dopamine modulation by stimulant self-administration. Front Biosci (Schol Ed). 2013;5:261-276.

89. Rothman RB, Baumann MH, Dersch CM, et al. Amphetamine-type central nervous system stimulants release norepinephrine more potently than they release dopamine and serotonin. Synapse. 2001;39(1): $32-41$.

90. Cruickshank CC, Dyer KR. A review of the clinical pharmacology of methamphetamine. Addiction. 2009;104(7):1085-1099.

91. National Institute on Drug Abuse. Cocaine: Abuse and Addiction. Bethesda (MD): NIDA; 2010.

92. National Institute on Drug Abuse. Methamphetamine Abuse and Addiction. Bethesda (MD): NIDA; 2006.

93. Hando J, Topp L, Hall W. Amphetamine-related harms and treatment preferences of regular amphetamine users in Sydney, Australia. Drug Alcohol Depend. 1997;46(1-2):105-113.

94. Rusyniak DE. Neurologic manifestations of chronic methamphetamine abuse. Neurol Clin. 2011;29(3):641-655.

95. Ciccarone D. Stimulant abuse: pharmacology, cocaine, methamphetamine, treatment, attempts at pharmacotherapy. Prim Care. 2011;38(1): $41-58$.

96. Jufer RA, Wstadik A, Walsh SL, Levine BS, Cone EJ. Elimination of cocaine and metabolites in plasma, saliva, and urine following repeated oral administration to human volunteers. J Anal Toxicol. 2000;24(7): 467-477. 
97. Hatsukami DK, Fischman MW. Crack cocaine and cocaine hydrochloride. Are the differences myth or reality? JAMA. 1996;276(19): $1580-1588$.

98. Volkow ND, Wang GJ, Fischman MW, et al. Effects of route of administration on cocaine induced dopamine transporter blockade in the human brain. Life Sci. 2000;67(12):1507-1515.

99. National Institute on Drug Abuse. Prescription drugs. Available from: http://www.drugabuse.gov/drugs-abuse/prescription-drugs. Accessed October 5, 2012.

100. Kish SJ. Pharmacologic mechanisms of crystal meth. CMAJ. 2008;178(13):1679-1682.

101. Harris DS, Boxenbaum H, Everhart ET, Sequeira G, Mendelson JE, Jones RT. The bioavailability of intranasal and smoked methamphetamine. Clin Pharmacol Ther. 2003;74(5):475-486.

102. Food and Drug Administration. Adderall (CII). 2007. Available from: http://www.accessdata.fda.gov/drugsatfda_docs/label/2007/ 011522s040lbl.pdf. Accessed December 19, 2012.

103. Goodwin JS, Larson GA, Swant J, et al. Amphetamine and methamphetamine differentially affect dopamine transporters in vitro and in vivo. J Biol Chem. 2009;284(5):2978-2989.

104. Melega WP, Williams AE, Schmitz DA, DiStefano EW, Cho AK. Pharmacokinetic and pharmacodynamic analysis of the actions of D-amphetamine and D-methamphetamine on the dopamine terminal. J Pharmacol Exp Ther. 1995;274(1):90-96.

105. Ross S, Peselow E. The neurobiology of addictive disorders. Clin Neuropharmacol. 2009;32(5):269-276.

106. Gamberino WC, Gold MS. Neurobiology of tobacco smoking and other addictive disorders. Psychiatr Clin North Am. 1999;22(2):301-312.

107. Van den Oever MC, Spijker S, Smit AB. The synaptic pathology of drug addiction. Adv Exp Med Biol. 2012;970:469-491.

108. Madoz-Gurpide A, Blasco-Fontecilla H, Baca-Garcia E, Ochoa-Mangado E. Executive dysfunction in chronic cocaine users: an exploratory study. Drug Alcohol Depend. 2011;117(1):55-58.

109. Henry BL, Minassian A, Perry W. Effect of methamphetamine dependence on everyday functional ability. Addict Behav. 2010;35(6): 593-598.

110. Hosak L, Preiss M, Bazant J, Tibenska A, Cermakova R, Cermakova E. Comparison of Wisconsin card sorting test results between Czech subjects dependent on methamphetamine versus healthy volunteers. Psychiatr Danub. 2012;24(2):188-193.

111. Kim YT, Kwon DH, Chang Y. Impairments of facial emotion recognition and theory of mind in methamphetamine abusers. Psychiatry Res. 2011;186(1):80-84.

112. Camchong J, MacDonald AW 3rd, Nelson B, et al. Frontal hyperconnectivity related to discounting and reversal learning in cocaine subjects. Biol Psychiatry. 2011;69(11):1117-1123.

113. Ersche KD, Roiser JP, Robbins TW, Sahakian BJ. Chronic cocaine but not chronic amphetamine use is associated with perseverative responding in humans. Psychopharmacology (Berl). 2008;197(3):421-431.

114. Iudicello JE, Woods SP, Vigil O, et al. Longer term improvement in neurocognitive functioning and affective distress among methamphetamine users who achieve stable abstinence. J Clin Exp Neuropsychol. 2010;32(7):704-718.

115. Morgan EE, Woods SP, Poquette AJ, Vigil O, Heaton RK, Grant I. Visual memory in methamphetamine-dependent individuals: deficient strategic control of encoding and retrieval. Aust N Z J Psychiatry. 2012;46(2):141-152.

116. Woods SP, Rippeth JD, Conover E, et al. Deficient strategic control of verbal encoding and retrieval in individuals with methamphetamine dependence. Neuropsychology. 2005;19(1):35-43.

117. Rolls ET. The representation of information about faces in the temporal and frontal lobes. Neuropsychologia. 2007;45(1):124-143.

118. Tolliver BK, Price KL, Baker NL, et al. Impaired cognitive performance in subjects with methamphetamine dependence during exposure to neutral versus methamphetamine-related cues. Am J Drug Alcohol Abuse. 2012;38(3):251-259.
119. Kuzenko N, Sareen J, Beesdo-Baum K, et al. Associations between use of cocaine, amphetamines, or psychedelics and psychotic symptoms in a community sample. Acta Psychiatr Scand. 2011;123(6): 466-474.

120. Lichlyter B, Purdon S, Tibbo P. Predictors of psychosis severity in individuals with primary stimulant addictions. Addict Behav. 2011; 36(1-2):137-139.

121. Mahoney JJ 3rd, Hawkins RY, De La Garza R 2nd, Kalechstein AD, Newton TF. Relationship between gender and psychotic symptoms in cocaine-dependent and methamphetamine-dependent participants. Gend Med. 2010;7(5):414-421.

122. Copeland AL, Sorensen JL. Differences between methamphetamine users and cocaine users in treatment. Drug Alcohol Depend. 2001; 62(1):91-95.

123. Cohen AL, Shuler C, McAllister S, et al. Methamphetamine use and methicillin-resistant Staphylococcus aureus skin infections. Emerg Infect Dis. 2007;13(11):1707-1713.

124. Siegel RK. Cocaine hallucinations. Am J Psychiatry. 1978;135(3): 309-314.

125. Rylander G. Psychoses and the punding and choreiform syndromes in addiction to central stimulant drugs. Psychiatr Neurol Neurochir. 1972;75(3):203-212.

126. Fasano A, Barra A, Nicosia P, et al. Cocaine addiction: from habits to stereotypical-repetitive behaviors and punding. Drug Alcohol Depend. 2008;96(1-2):178-182.

127. Rhee KJ, Albertson TE, Douglas JC. Choreoathetoid disorder associated with amphetamine-like drugs. Am J Emerg Med. 1988;6(2): $131-133$

128. Bartzokis G, Beckson M, Wirshing DA, Lu PH, Foster JA, Mintz J. Choreoathetoid movements in cocaine dependence. Biol Psychiatry. 1999;45(12):1630-1635.

129. Gu H, Salmeron BJ, Ross TJ, et al. Mesocorticolimbic circuits are impaired in chronic cocaine users as demonstrated by resting-state functional connectivity. Neuroimage. 2010;53(2):593-601.

130. Hester R, Garavan H. Executive dysfunction in cocaine addiction: evidence for discordant frontal, cingulate, and cerebellar activity. J Neurosci. 2004;24(49):11017-11022.

131. Kübler A, Murphy K, Garavan H. Cocaine dependence and attention switching within and between verbal and visuospatial working memory. Eur J Neurosci. 2005;21(7):1984-1992.

132. Tomasi D, Volkow ND, Wang R, et al. Disrupted functional connectivity with dopaminergic midbrain in cocaine abusers. PLoS One. 2010;5(5):e10815.

133. Bustamante JC, Barrós-Loscertales A, Ventura-Campos N, et al. Right parietal hypoactivation in a cocaine-dependent group during a verbal working memory task. Brain Res. 2011;1375:111-119.

134. Wilcox CE, Teshiba TM, Merideth F, Ling J, Mayer AR. Enhanced cue reactivity and fronto-striatal functional connectivity in cocaine use disorders. Drug Alcohol Depend. 2011;115(1-2):137-144.

135. Hanlon CA, Wesley MJ, Roth AJ, Miller MD, Porrino LJ. Loss of laterality in chronic cocaine users: an fMRI investigation of sensorimotor control. Psychiatry Res. 2010;181(1):15-23.

136. Hanlon CA, Dufault DL, Wesley MJ, Porrino LJ. Elevated gray and white matter densities in cocaine abstainers compared to current users. Psychopharmacology (Berl). 2011;218(4):681-692.

137. Tanabe J, Tregellas JR, Dalwani M, et al. Medial orbitofrontal cortex gray matter is reduced in abstinent substance-dependent individuals. Biol Psychiatry. 2009;65(2):160-164.

138. Lane SD, Steinberg JL, Ma L, et al. Diffusion tensor imaging and decision making in cocaine dependence. PLoS One. 2010;5(7):e11591.

139. Tobias MC, O’Neill J, Hudkins M, Bartzokis G, Dean AC, London ED. White-matter abnormalities in brain during early abstinence from methamphetamine abuse. Psychopharmacology (Berl). 2010;209(1):13-24.

140. Salo R, Nordahl TE, Buonocore MH, et al. Cognitive control and white matter callosal microstructure in methamphetamine-dependent subjects: a diffusion tensor imaging study. Biol Psychiatry. 2009;65(2): 122-128. 
141. Thompson PM, Hayashi KM, Simon SL, et al. Structural abnormalities in the brains of human subjects who use methamphetamine. J Neurosci. 2004;24(26):6028-6036.

142. Bartzokis G, Beckson M, Lu PH, et al. Age-related brain volume reductions in amphetamine and cocaine addicts and normal controls: implications for addiction research. Psychiatry Res. 2000;98(2):93-102.

143. Rajesh N, Diana M. Cocaine abuse and sensitization of striatal dopamine transmission: a critical review of the preclinical and clinical imaging literature. Synapse. 2008;62(11):851-869.

144. Hitri A, Casanova MF, Kleinman JE, Wyatt RJ. Fewer dopamine transporter receptors in the prefrontal cortex of cocaine users. Am J Psychiatry. 1994;151(7):1074-1076.

145. Kitamura O. Detection of methamphetamine neurotoxicity in forensic autopsy cases. Leg Med (Tokyo). 2009;11 Suppl 1:S63-S65.

146. Wilson JM, Kalasinsky KS, Levey AI, et al. Striatal dopamine nerve terminal markers in human, chronic methamphetamine users. Nat Med. 1996;2(6):699-703.

147. Little KY, Krolewski DM, Zhang L, Cassin BJ. Loss of striatal vesicular monoamine transporter protein (VMAT2) in human cocaine users. Am J Psychiatry. 2003;160(1):47-55.

148. Wilson JM, Levey AI, Bergeron C, et al. Striatal dopamine, dopamine transporter, and vesicular monoamine transporter in chronic cocaine users. Ann Neurol. 1996;40(3):428-439.

149. Staley JK, Talbot JZ, Ciliax BJ, et al. Radioligand binding and immunoautoradiographic evidence for a lack of toxicity to dopaminergic nerve terminals in human cocaine overdose victims. Brain Res. 1997; 747(2):219-229.

150. Narendran R, Lopresti BJ, Martinez D, et al. In vivo evidence for low striatal vesicular monoamine transporter 2 (VMAT2) availability in cocaine abusers. Am J Psychiatry. 2012;169(1):55-63.

151. Martinez D, Narendran R, Foltin RW, et al. Amphetamine-induced dopamine release: markedly blunted in cocaine dependence and predictive of the choice to self-administer cocaine. Am J Psychiatry. 2007; 164(4):622-629.

152. Volkow ND, Wang GJ, Fowler JS, et al. Decreased striatal dopaminergic responsiveness in detoxified cocaine-dependent subjects. Nature. 1997;386(6627):830-833.

153. Wu JC, Bell K, Najafi A, et al. Decreasing striatal 6-FDOPA uptake with increasing duration of cocaine withdrawal. Neuropsychopharmacology. 1997;17(6):402-409.

154. Martinez D, Broft A, Foltin RW, et al. Cocaine dependence and d2 receptor availability in the functional subdivisions of the striatum: relationship with cocaine-seeking behavior. Neuropsychopharmacology. 2004;29(6):1190-1202.

155. Volkow ND, Fowler JS, Wang GJ, et al. Decreased dopamine d2 receptor availability is associated with reduced frontal metabolism in cocaine abusers. Synapse. 1993;14(2):169-177.

156. Volkow ND, Chang L, Wang GJ, et al. Low level of brain dopamine $\mathrm{d} 2$ receptors in methamphetamine abusers: association with metabolism in the orbitofrontal cortex. Am J Psychiatry. 2001;158(12):2015-2021.

157. Boileau I, Rusjan P, Houle S, et al. Increased vesicular monoamine transporter binding during early abstinence in human methamphetamine users: is VMAT2 a stable dopamine neuron biomarker? J Neurosci. 2008;28(39):9850-9856.

158. Johanson CE, Frey KA, Lundahl LH, et al. Cognitive function and nigrostriatal markers in abstinent methamphetamine abusers. Psychopharmacology (Berl). 2006;185(3):327-338.

159. Sekine Y, Minabe Y, Ouchi Y, et al. Association of dopamine transporter loss in the orbitofrontal and dorsolateral prefrontal cortices with methamphetamine-related psychiatric symptoms. Am J Psychiatry. 2003;160(9):1699-1701.

160. Sekine Y, Iyo M, Ouchi Y, et al. Methamphetamine-related psychiatric symptoms and reduced brain dopamine transporters studied with PET. Am J Psychiatry. 2001;158(8):1206-1214.

161. Volkow ND, Chang L, Wang GJ, et al. Higher cortical and lower subcortical metabolism in detoxified methamphetamine abusers. Am J Psychiatry. 2001;158(3):383-389.
162. Volkow ND, Chang L, Wang GJ, et al. Loss of dopamine transporters in methamphetamine abusers recovers with protracted abstinence. J Neurosci. 2001;21(23):9414-9418.

163. Krasnova IN, Cadet JL. Methamphetamine toxicity and messengers of death. Brain Res Rev. 2009;60(2):379-407.

164. LaVoie MJ, Hastings TG. Dopamine quinone formation and protein modification associated with the striatal neurotoxicity of methamphetamine: evidence against a role for extracellular dopamine. J Neurosci. 1999;19(4):1484-1491.

165. De Vito MJ, Wagner GC. Methamphetamine-induced neuronal damage: a possible role for free radicals. Neuropharmacology. 1989; 28(10):1145-1150.

166. Thomas DM, Dowgiert J, Geddes TJ, Francescutti-Verbeem D, Liu X, Kuhn DM. Microglial activation is a pharmacologically specific marker for the neurotoxic amphetamines. Neurosci Lett. 2004;367(3):349-354.

167. Kitamura O, Takeichi T, Wang EL, Tokunaga I, Ishigami A, Kubo S. Microglial and astrocytic changes in the striatum of methamphetamine abusers. Leg Med (Tokyo). 2010;12(2):57-62.

168. Sekine Y, Ouchi Y, Sugihara G, et al. Methamphetamine causes microglial activation in the brains of human abusers. J Neurosci. 2008; 28(22):5756-5761.

169. Loftis JM, Choi D, Hoffman W, Huckans MS. Methamphetamine causes persistent immune dysregulation: a cross-species, translational report. Neurotox Res. 2011;20(1):59-68.

170. Fox HC, D'Sa C, Kimmerling A, et al. Immune system inflammation in cocaine dependent individuals: implications for medications development. Hum Psychopharmacol. 2012;27(2):156-166.

171. Alvaro-Bartolomé M, La Harpe R, Callado LF, Meana JJ, García-Sevilla JA. Molecular adaptations of apoptotic pathways and signaling partners in the cerebral cortex of human cocaine addicts and cocaine-treated rats. Neuroscience. 2011;196:1-15.

172. Kampman KM, Leiderman D, Holmes T, et al. Cocaine Rapid Efficacy Screening Trials (CREST): lessons learned. Addiction. 2005;100 Suppl 1:102-110.

173. Amato L, Minozzi S, Pani PP, et al. Dopamine agonists for the treatment of cocaine dependence. Cochrane Database Syst Rev. 2011;12: CD003352.

174. NewmanAH, Blaylock BL, Nader MA, Bergman J, Sibley DR, Skolnick P. Medication discovery for addiction: translating the dopamine d3 receptor hypothesis. Biochem Pharmacol. 2012;84(7): 882-890.

175. Feltenstein MW, See RE. The neurocircuitry of addiction: an overview. Br J Pharmacol. 2008;154(2):261-274.

176. Meini M, Moncini M, Cecconi D, et al. Aripiprazole and ropinirole treatment for cocaine dependence: evidence from a pilot study. Curr Pharm Des. 2011;17(14):1376-1383.

177. Haney M, Rubin E, Foltin RW. Aripiprazole maintenance increases smoked cocaine self-administration in humans. Psychopharmacology (Berl). 2011;216(3):379-387.

178. Baker DA, Shen H, Kalivas PW. Cystine/glutamate exchange serves as the source for extracellular glutamate: modifications by repeated cocaine administration. Amino Acids. 2002;23(1-3): 161-162.

179. Baker DA, McFarland K, Lake RW, Shen H, Toda S, Kalivas PW. $\mathrm{N}$-acetyl cysteine-induced blockade of cocaine-induced reinstatement. Ann NY Acad Sci. 2003;1003:349-351.

180. Mardikian PN, LaRowe SD, Hedden S, Kalivas PW, Malcolm RJ. An open-label trial of n-acetylcysteine for the treatment of cocaine dependence: a pilot study. Prog Neuropsychopharmacol Biol Psychiatry. 2007;31(2):389-394.

181. LaRowe SD, Myrick $\mathrm{H}$, Hedden $\mathrm{S}$, et al. Is cocaine desire reduced by N-acetylcysteine? Am J Psychiatry. 2007;164(7):1115-1117.

182. Schmaal L, Veltman DJ, Nederveen A, van den Brink W, Goudriaan AE. $\mathrm{N}$-acetylcysteine normalizes glutamate levels in cocaine-dependent patients: a randomized crossover magnetic resonance spectroscopy study. Neuropsychopharmacology. 2012;37(9):2143-2152. 
183. Elkashef A, Kahn R, Yu E, et al. Topiramate for the treatment of methamphetamine addiction: a multi-center placebo-controlled trial. Addiction. 2012;107(7):1297-1306.

184. Elkashef AM, Rawson RA, Anderson AL, et al. Bupropion for the treatment of methamphetamine dependence. Neuropsychopharmacology. 2008;33(5):1162-1170.

185. Kreek MJ, LaForge KS, Butelman E. Pharmacotherapy of addictions. Nat Rev Drug Discov. 2002;1(9):710-726.

186. Karila L, Gorelick D, Weinstein A, et al. New treatments for cocaine dependence: a focused review. Int J Neuropsychopharmacol. 2008; 11(3):425-438.

187. Brackins T, Brahm NC, Kissack JC. Treatments for methamphetamine abuse: a literature review for the clinician. J Pharm Pract. 2011;24(6): 541-550.

188. Vocci F, Ling W. Medications development: successes and challenges. Pharmacol Ther. 2005;108(1):94-108.

189. Pani PP, Trogu E, Vecchi S, Amato L. Antidepressants for cocaine dependence and problematic cocaine use. Cochrane Database Syst Rev. 2011;12:CD002950.

190. van den Brink W, van Ree JM. Pharmacological treatments for heroin and cocaine addiction. Eur Neuropsychopharmacol. 2003;13(6): 476-487.

191. Poling J, Rounsaville B, Gonsai K, Severino K, Sofuoglu M. The safety and efficacy of varenicline in cocaine using smokers maintained on methadone: a pilot study. Am J Addict. 2010;19(5):401-408.

192. Plebani JG, Lynch KG, Yu Q, Pettinati HM, O’Brien CP, Kampman KM. Results of an initial clinical trial of varenicline for the treatment of cocaine dependence. Drug Alcohol Depend. 2012;121(1-2): $163-166$.

193. Jobes ML, Ghitza UE, Epstein DH, Phillips KA, Heishman SJ, Preston KL. Clonidine blocks stress-induced craving in cocaine users. Psychopharmacology (Berl). 2011;218(1):83-88.

194. Colfax GN, Santos GM, Das M, et al. Mirtazapine to reduce methamphetamine use: a randomized controlled trial. Arch Gen Psychiatry. 2011;68(11):1168-1175.

195. Gysling K. Relevance of both type-1 and type- 2 corticotropin releasing factor receptors in stress-induced relapse to cocaine seeking behaviour. Biochem Pharmacol. 2012;83(1):1-5.

196. Aston-Jones G, Smith RJ, Sartor GC, et al. Lateral hypothalamic orexin/hypocretin neurons: a role in reward-seeking and addiction. Brain Res. 2010;1314:74-90.

197. Parolaro D, Rubino T. The role of the endogenous cannabinoid system in drug addiction. Drug News Perspect. 2008;21(3):149-157.

198. Sofuoglu M, DeVito EE, Waters AJ, Carroll KM. Cognitive enhancement as a treatment for drug addictions. Neuropharmacology. 2013;64:452-463.

199. Nic Dhonnchadha BA, Kantak KM. Cognitive enhancers for facilitating drug cue extinction: insights from animal models. Pharmacol Biochem Behav. 2011;99(2):229-244.
200. Sofuoglu M. Cognitive enhancement as a pharmacotherapy target for stimulant addiction. Addiction. 2010;105(1):38-48.

201. Castells X, Casas M, Perez-Mana C, Roncero C, Vidal X, Capella D. Efficacy of psychostimulant drugs for cocaine dependence. Cochrane Database Syst Rev. 2010;2:CD007380.

202. Mariani JJ, Levin FR. Psychostimulant treatment of cocaine dependence. Psychiatr Clin North Am. 2012;35(2):425-439.

203. Levin FR, Evans SM, Brooks DJ, Garawi F. Treatment of cocaine dependent treatment seekers with adult ADHD: double-blind comparison of methylphenidate and placebo. Drug Alcohol Depend. 2007;87(1):20-29.

204. Heinzerling KG, Swanson AN, Kim S, et al. Randomized, double-blind, placebo-controlled trial of modafinil for the treatment of methamphetamine dependence. Drug Alcohol Depend. 2010;109(1-3):20-29.

205. Shearer J, Darke S, Rodgers C, et al. A double-blind, placebo-controlled trial of modafinil (200 mg/day) for methamphetamine dependence. Addiction. 2009;104(2):224-233.

206. Sofuoglu M, Carroll KM. Effects of galantamine on cocaine use in chronic cocaine users. Am J Addict. 2011;20(3):302-303.

207. Sofuoglu M, Waters AJ, Poling J, Carroll KM. Galantamine improves sustained attention in chronic cocaine users. Exp Clin Psychopharmacol. 2011;19(1):11-19.

208. Haile CN, Kosten TR, Kosten TA. Pharmacogenetic treatments for drug addiction: cocaine, amphetamine and methamphetamine. Am J Drug Alcohol Abuse. 2009;35(3):161-177.

209. Narasimhan D, Woods JH, Sunahara RK. Bacterial cocaine esterase: a protein-based therapy for cocaine overdose and addiction. Future Med Chem. 2012;4(2):137-150.

210. Shen X, Kosten TR. Immunotherapy for drug abuse. CNS Neurol Disord Drug Targets. 2011;10(8):876-879.

211. Robison AJ, Nestler EJ. Transcriptional and epigenetic mechanisms of addiction. Nat Rev Neurosci. 2011;12(11):623-637.

212. Hyman SE. Revolution stalled. Sci Transl Med. 2012;4(155): $155 \mathrm{~cm} 111$

213. Insel TR. Next-generation treatments for mental disorders. Sci Transl Med. 2012;4(155):155ps19.

214. Subramaniam K, Luks TL, Fisher M, Simpson GV, Nagarajan S, Vinogradov S. Computerized cognitive training restores neural activity within the reality monitoring network in schizophrenia. Neuron. 2012;73(4):842-853.

215. Eldar S, Apter A, Lotan D, et al. Attention bias modification treatment for pediatric anxiety disorders: a randomized controlled trial. Am J Psychiatry. 2012;169(2):213-220.

216. Amir N, Taylor CT. Combining computerized home-based treatments for generalized anxiety disorder: an attention modification program and cognitive behavioral therapy. Behav Ther. 2012;43(3):546-559.

Substance Abuse and Rehabilitation

\section{Publish your work in this journal}

Substance Abuse and Rehabilitation is an international, peer-reviewed, open access journal publishing original research, case reports, editorials, reviews and commentaries on all areas of addiction and substance abuse and options for treatment and rehabilitation. The manuscript management system is completely online and includes a very quick and fair 